\title{
Persistence of Experience-Induced Homeostatic Synaptic Plasticity through Adulthood in Superficial Layers of Mouse Visual Cortex
}

\author{
Anubhuthi Goel ${ }^{1,2}$ and Hey-Kyoung Lee ${ }^{1,2}$ \\ ${ }^{1}$ Department of Biology, College of Chemical and Life Sciences, and ${ }^{2}$ Neuroscience and Cognitive Science Program, University of Maryland, College Park, \\ Maryland 20742
}

\begin{abstract}
It is well established that sensory cortices of animals can be modified by sensory experience, especially during a brief early critical period in development. Theoretical analyses indicate that there are two synaptic plasticity mechanisms required: input-specific synaptic modifications and global homeostatic mechanisms to provide stability to neural networks. Experience-dependent homeostatic synaptic plasticity mechanisms have subsequently been demonstrated in the visual cortex of juvenile animals. Here, we report that experiencedependent homeostatic synaptic plasticity persists through adulthood in the superficial layers of the mouse visual cortex. We found that $2 \mathrm{~d}$ of visual deprivation in the form of dark rearing is necessary and sufficient to cause an increase in AMPA receptor-mediated miniature EPSC amplitude in layer $2 / 3$ neurons. This increase was rapidly reversed by $1 \mathrm{~d}$ of light exposure. This reversible change in synaptic strength persisted in adult mice past the critical period for ocular dominance plasticity, which is reported to end at $\sim 1$ month of age in rodents. Interestingly, the mechanism of homeostatic synaptic modifications in 3-month-old mice differed from that in young mice (3 weeks old) in that the multiplicative nature of synaptic scaling is lost. Our results demonstrate that the superficial layers of adult mouse visual cortex retain the ability to undergo reversible experience-dependent homeostatic synaptic plasticity.
\end{abstract}

Key words: homeostatic plasticity; mEPSC; critical period; reversible modification; dark rearing; multiplicative

\section{Introduction}

Many functions of the brain depend on changes in synaptic connectivity. Research on synaptic plasticity has focused on activitydependent changes that are rapid and occur locally at specific synapses, such as long-term potentiation and long-term depression (Bliss and Collingridge, 1993; Malenka and Bear, 2004). However, it was recognized early on that such synapse-specific plasticity has to be counter-balanced by a more global homeostatic mechanism to maintain stability in neural networks (Bienenstock et al., 1982; Bear et al., 1987; Abbott and Nelson, 2000; Turrigiano and Nelson, 2004). One of the homeostatic mechanisms that have been proposed is synaptic scaling (Turrigiano and Nelson, 2004), where a prolonged increase in neural activity globally scales down excitatory synaptic responses, while a chronic decrease in activity scales up the responses. Homeostatic synaptic scaling was initially demonstrated in vitro where excitatory synaptic strengths in cultured neurons adapt to prolonged changes in neural activity by pharmacological manipulations (Lissin et al., 1998; O'Brien et al., 1998; Turrigiano et al., 1998; Thiagarajan et al., 2002; Ju et al., 2004). This has been extended in vivo where several days of visual deprivation in-

\footnotetext{
Received Nov. 20, 2006; revised April 25, 2007; accepted May 16, 2007.

This work was supported by National Institutes of Health Grant R01-EY014882 and the Sloan Research Fellowship to H.L.

Correspondence should be addressed to Dr. Hey-Kyoung Lee at the above address. E-mail: hlee21@umd.edu. DOI:10.1523/JNEUROSCI.5038-06.2007

Copyright $\odot 2007$ Society for Neuroscience $\quad 0270-6474 / 07 / 276692-09 \$ 15.00 / 0$
}

creases excitatory synaptic transmission in visual cortical neurons in juvenile rats (Desai et al., 2002; Goel et al., 2006), which rapidly reverses with a few days of visual experience (Goel et al., 2006).

The majority of studies on homeostatic synaptic plasticity have been conducted in young animals within the "critical period." Therefore, it is not known whether it persists through adulthood. From the pioneering work of Wiesel and Hubel (1963), the concept of the "critical period" was proposed, which is defined as a distinct window during development when synaptic connections can be sculpted by experience. Whereas previous studies emphasized the enhanced plasticity during the critical period (Wiesel and Hubel, 1963; LeVay et al., 1980; Hubel, 1982; Gordon and Stryker, 1996), more recent evidence showed that the critical period closure is not absolute, and may even be reversed. For example, a brief MD paradigm in rodents only produces OD plasticity within a critical period (Gordon and Stryker, 1996), but a slightly longer duration of MD (5 d) causes a robust OD shift in adults [postnatal day (P90)] (Sawtell et al., 2003). Moreover, preceding a brief MD with a prolonged binocular deprivation in adult rats induces a "juvenile-like" OD plasticity ( $\mathrm{He}$ et al., 2006). Although these findings demonstrate that adult cortex retains the ability to undergo experience-dependent plasticity, there seem to be differences across layers, where layer $2 / 3$ retains the ability to undergo plasticity longer than layer 4 (LeVay et al., 1980; Daw et al., 1992; Guire et al., 1999; Pham et al., 2004). Laminar difference is also reported for homeostatic synaptic scal- 
a

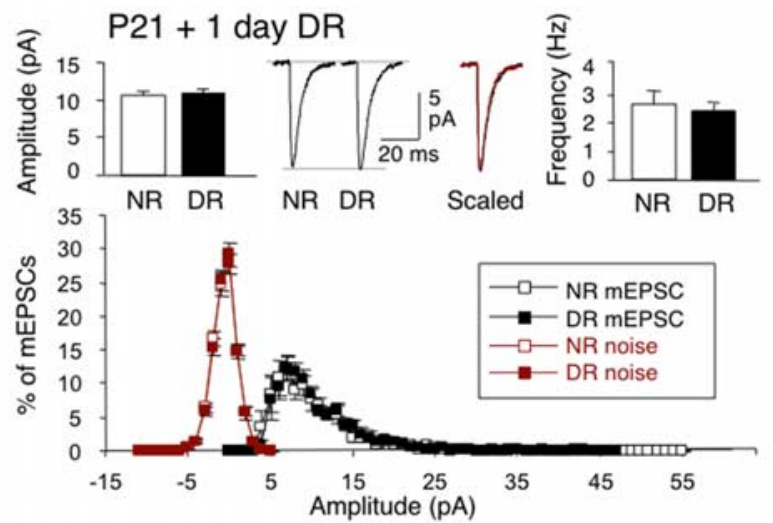

b

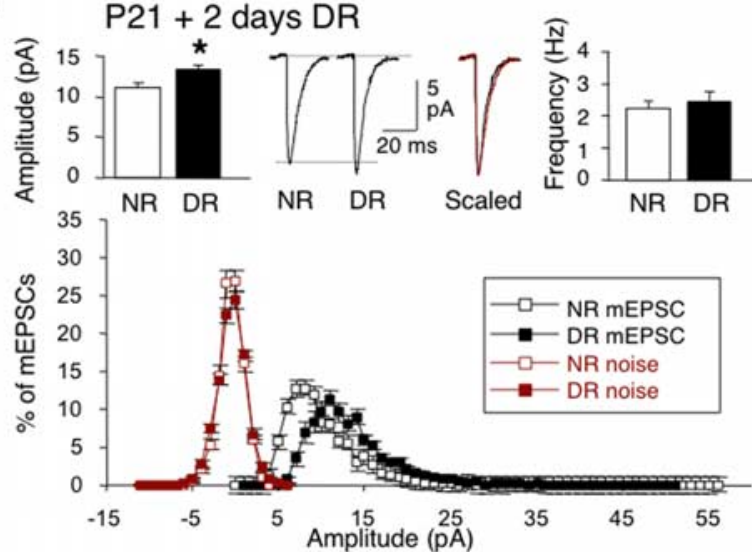

C
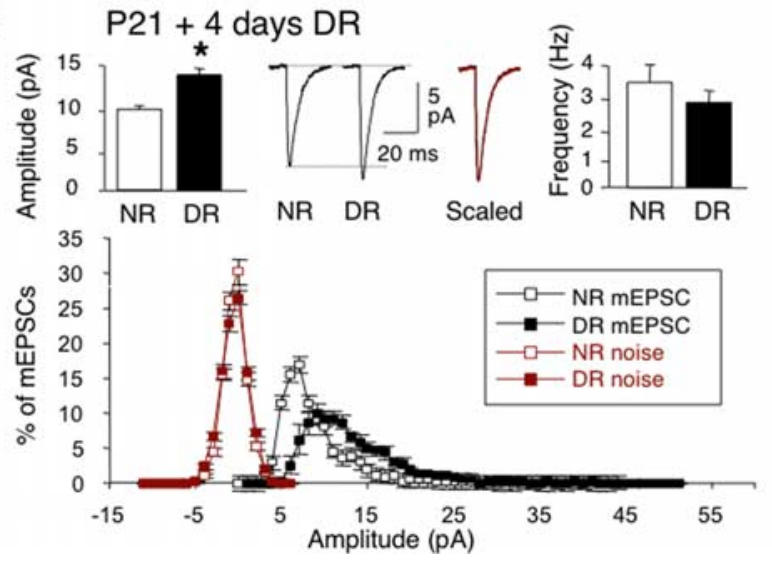

P25 NR

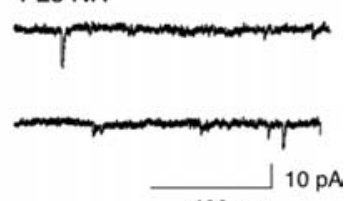

$\mathrm{P} 21+4 \mathrm{~d}$ DR

$400 \mathrm{~ms}$

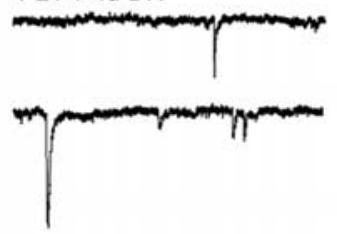

Figure 1. The minimum duration of dark rearing necessary and sufficient to maximally increase AMPA receptor-mediated $\mathrm{mEPSC}$ in layer 2/3 neurons is $2 \mathrm{~d}$. $\boldsymbol{a}$, Dark rearing P21 mice for $1 \mathrm{~d}$ did not significantly change mEPSC amplitude or frequency in layer 2/3 neurons. Top left, Comparison of average mEPSC amplitude of cells from P22 NR and $1 \mathrm{~d}$ DR (from P21 to P22) mice. Top middle, Average mEPSC traces from NR (left trace) and $1 \mathrm{~d}$ DR (right trace) mice. "Scaled" indicates the NR mEPSC average trace scaled (red trace) to match in amplitude that of the $1 \mathrm{~d}$ DR and superimposed on the $1 \mathrm{~d}$ DR average trace (black trace). Note that there was no difference in mEPSC kinetics. Top right, Comparison of average mEPSC frequency from cells from NR and $1 \mathrm{~d} D R$ mice. Bottom, Distribution histogram of mEPSC amplitudes recorded from NR (open black symbols) and $1 \mathrm{~d}$ DR mice (closed black symbols). There was no change in the distribution of mEPSC amplitudes recorded from $1 \mathrm{~d}$ DR and NR mice. The distribution histogram also clearly shows that there was no overlap between signal and noise and that there is no difference in noise levels between the two groups (open red symbols, NR noise; closed red symbols, dark-rearing noise). Far right, Representative traces of $\mathrm{mEPSC}$ recording obtained from layer 2/3 pyramidal cells of normally reared P22 mice (top two traces), and P21 mice dark reared for $1 \mathrm{~d}$ (bottom two traces). $\boldsymbol{b}$, Dark rearing P21 mice for $2 \mathrm{~d}$ increased the amplitude of mEPSCs without affecting mEPSC frequency. Top left, Comparison of average mEPSC amplitude of cells. Average mEPSC amplitude from P23 NR mice was significantly different from mice dark reared for $2 \mathrm{~d}$ from P21 to P23. Top middle, Average mEPSC traces from NR (left trace) and $2 \mathrm{~d}$ DR mice (right trace). "Scaled" indicates the NR mEPSC average trace scaled (red trace) and superimposed on the DR average trace (black trace). Top right, Comparison of average mEPSC frequency from cells from NR and $1 \mathrm{~d}$ DR mice. Bottom, Distribution histogram of mEPSCs recorded from $2 \mathrm{~d}$ DR mice (closed black symbols) showed a higher percentage of mEPSCs with larger amplitudes (i.e., shift in distribution toward larger amplitudes) compared with NR (open black symbols). There was no difference between distribution of NR noise (open red symbols) and dark-rearing noise (closed red symbols). Far right, Representative traces of mEPSC recording obtained from layer 2/3 pyramidal cells of normal reared P23 mice (top two traces) and P21 mice dark reared for $2 \mathrm{~d}$ (bottom two traces). c, Dark rearing P21 mice for $4 \mathrm{~d}$ increased mEPSC amplitude without changes in frequency. Top left, ing induced by visual deprivation in rats, where layer 4 scaling occurs only before $\mathrm{P} 21$, whereas layer $2 / 3$ scaling is observed only after this age (Desai et al., 2002). The major focus of this study was to determine whether experience-induced homeostatic synaptic plasticity persists through adulthood in the superficial layers of visual cortex.

\section{Materials and Methods}

Dark rearing animals. C57BL/6J mice (The Jackson Laboratory, Bar Harbor, ME) were raised in a normally lighted environment $(12 \mathrm{~h}$ light/dark cycle). Dark rearing was initiated at P11, P21, P36, or P95 for durations of 1, 2, or $4 \mathrm{~d}$. Control [normally reared (NR)] animals were continuously raised in the normal light condition for the same duration. The animals in the dark were cared for using infrared vision goggles under dim infrared light. A group of dark-reared (DR) mice were taken out to the lighted environment for $1 \mathrm{~d}$ to study the effect of re-exposure to light $(\mathrm{D}+\mathrm{L})$.

Preparation of visual cortical slices. Each animal was deeply anesthetized by placing it in a chamber with halothane vapors. The brain was rapidly removed and immersed in ice-cold dissection buffer [containing (in $\mathrm{mM}$ ) $212.7 \mathrm{su}$ crose, $5 \mathrm{KCl}, 1.25 \mathrm{NaH}_{2} \mathrm{PO}_{4}, 26 \mathrm{NaHCO}_{3}, 10$ glucose, $3 \mathrm{MgCl}_{2}, 1 \mathrm{CaCl}_{2}$ ] bubbled with $95 \%$ $\mathrm{O}_{2} / 5 \% \mathrm{CO}_{2}$ mixture. Older mice (P97) were transcardially perfused with ice-cold artificial CSF [ACSF; containing (in $\mathrm{mm}$ ) $124 \mathrm{NaCl}, 5$ $\mathrm{KCl}, 1.25 \mathrm{NaH}_{2} \mathrm{PO}_{4}, 26 \mathrm{NaHCO}_{3}, 10$ glucose, 1 $\mathrm{MgCl}_{2}, 2 \mathrm{CaCl}_{2}$ ] for $5-10 \mathrm{~min}$ at $0.8 \mathrm{ml} / \mathrm{min}$ before the removal of the brain. This greatly improved visualization of cells for whole-cell recordings. Blocks of primary visual cortices were rapidly dissected and sectioned in the coronal plane into $300-\mu \mathrm{m}$-thick slices using a Vibratome 3000 plus microslicer (Ted Pella, Redding, CA). The slices were collected in icecold dissection buffer and gently transferred to a submersion holding chamber with ACSF saturated with $95 \% \mathrm{O}_{2} / 5 \% \mathrm{CO}_{2}$. The slices were recovered for $\sim 1 \mathrm{~h}$ at room temperature before the recording.

Comparison of average $m$ EPSC amplitude of cells from P25 NR mice to that from mice dark reared for $4 \mathrm{~d}$ from P21 to P25 (DR). Top middle, Average mEPSC traces from NR (left trace) and $4 \mathrm{~d} \mathrm{DR}$ (right trace) mice. "Scaled" indicates the NR mEPSC average trace scaled (red trace) and superimposed on the $4 \mathrm{~d}$ DR average trace (black trace). Top right, No change in average mEPSC frequency from cells from NR and $4 \mathrm{~d}$ DR mice. Bottom, Distribution histogram of mEPSC amplitudes recorded from $4 \mathrm{~d}$ DR mice (closed black symbols) shows a higher percentage of mEPSCs with larger amplitudes compared with NR animals (open black symbols). There was no difference between distribution of NR noise (open red symbols) and DR noise (closed red symbols). Far right, Representative traces of $\mathrm{mEPSC}$ recording obtained from layer $2 / 3$ pyramidal cells of normally reared $\mathrm{P} 25$ mice (top two traces) and P21 mice dark reared for $4 \mathrm{~d}$ (bottom two traces). ${ }^{*} p<0.04$ with $t$ test. 
Table 1. Neuronal properties

\begin{tabular}{llllll}
\hline Age $(\mathrm{d})$ & Conditions & $\begin{array}{l}\text { Rise time } 10-90 \% \\
(\mathrm{~ms})\end{array}$ & $\begin{array}{l}\text { Decay time constant } \\
(\tau)(\mathrm{ms})\end{array}$ & $R_{\text {in }}(\mathrm{M} \Omega)$ & $R_{\text {ser }}(\mathrm{M} \Omega)$ \\
\hline 13 & $\mathrm{NR}$ & $1.9 \pm 0.1$ & $5.02 \pm 0.2$ & $375 \pm 39$ & $21.6 \pm 0.7$ \\
& $2 \mathrm{~d} \mathrm{DR}$ & $1.6 \pm 0.8$ & $4.4 \pm 0.3$ & $444 \pm 78$ & $20.9 \pm 1.3$ \\
22 & $\mathrm{NR}$ & $1.6 \pm 0.1$ & $4.02 \pm 0.3$ & $387 \pm 97$ & $20.6 \pm 1.2$ \\
& $1 \mathrm{~d} \mathrm{DR}$ & $1.7 \pm 0.1$ & $4.5 \pm 0.3$ & $302 \pm 35$ & $22.2 \pm 1.0$ \\
23 & $\mathrm{NR}$ & $1.7 \pm 0.04$ & $4.7 \pm 0.3$ & $307 \pm 36$ & $21.7 \pm 1.5$ \\
& $2 \mathrm{~d} \mathrm{DR}$ & $1.6 \pm 0.1$ & $4.04 \pm 0.2$ & $475 \pm 103$ & $21.6 \pm 1.4$ \\
& $2 \mathrm{~d} \mathrm{DR}+1 \mathrm{dL}$ & $1.7 \pm 0.04$ & $4.7 \pm 0.3$ & $283 \pm 36$ & $21.9 \pm 1.5$ \\
25 & $\mathrm{NR}$ & $1.8 \pm 0.1$ & $4.5 \pm 0.2$ & $490 \pm 126$ & $20.4 \pm 1.8$ \\
& $4 \mathrm{~d} \mathrm{DR}$ & $1.6 \pm 0.1$ & $4.3 \pm 0.2$ & $518 \pm 113$ & $21.1 \pm 1.1$ \\
38 & $\mathrm{NR}$ & $1.7 \pm 0.1$ & $4.5 \pm 0.2$ & $392 \pm 79$ & $18.8 \pm 0.7$ \\
& $2 \mathrm{~d} \mathrm{DR}$ & $1.5 \pm 0.1$ & $3.6 \pm 0.2^{*}$ & $492 \pm 99$ & $22.4 \pm 1.1$ \\
& $2 \mathrm{~d} \mathrm{DR}+1 \mathrm{dL}$ & $1.6 \pm 0.6$ & $4.4 \pm 0.2$ & $485 \pm 126$ & $20.3 \pm 0.6$ \\
40 & $\mathrm{NR}$ & $1.6 \pm 0.1$ & $4.4 \pm 0.3$ & $400 \pm 38$ & $17 \pm 0.9$ \\
& $4 \mathrm{~d} \mathrm{DR}$ & $1.3 \pm 0.1$ & $3.4 \pm 0.3^{*}$ & $413 \pm 88$ & $17.4 \pm 0.8$ \\
97 & $\mathrm{NR}$ & $1.5 \pm 0.1$ & $3.4 \pm 0.2$ & $359 \pm 55$ & $19.7 \pm 0.6$ \\
& $2 \mathrm{~d} \mathrm{DR}$ & $1.4 \pm 0.1$ & $4.1 \pm 0.3^{*}$ & $375 \pm 74$ & $19.8 \pm 0.7$ \\
& $2 \mathrm{~d} \mathrm{DR}+1 \mathrm{dL}$ & $1.6 \pm 0.1$ & $4.4 \pm 0.2^{*}$ & $701 \pm 230$ & $18.6 \pm 0.5$ \\
\hline
\end{tabular}

*Statistically significant difference from NR condition at $p<0.03$ with $t$ test or one-way ANOVA. $R_{\mathrm{in},}$ Input $R$; $R_{\text {ser, }}$ series $R$.

lead to maximal changes in AMPA receptor-mediated mEPSCs in layer $2 / 3$ pyramidal cells of mouse visual cortex. Studies in juvenile rats have shown that visual deprivation for $2 \mathrm{~d}$ by injecting TTX into one eye causes an increase in mEPSC amplitude of layer $2 / 3$ visual cortical neurons in the contralateral monocular zone (Desai et al., 2002). Nevertheless, the question of whether $2 \mathrm{~d}$ of visual deprivation is necessary remained unresolved. To determine this, mice of age P21 were binocularly deprived of visual input by dark rearing for 1,2 , and $4 \mathrm{~d}$, and mEPSCs recorded at P22 for $1 \mathrm{~d}$ DR (P21-P22), P23 for $2 \mathrm{~d} \mathrm{DR}$ (P21-P23), and P25 for $4 \mathrm{~d}$ DR (P21-P25) mice were compared with agematched NR control mice.

We found that $1 \mathrm{~d}$ of dark rearing failed to change mEPSC amplitude (P22, NR, $11.5 \pm 0.9 \mathrm{pA}, n=9 ; \mathrm{DR}, 11.7 \pm 0.7 \mathrm{pA}$,

Whole-cell recording of AMPA receptor-mediated mEPSCs. The visual cortical slices were moved to a submersion recording chamber mounted on a stage of an upright microscope (E600 FN; Nikon, Tokyo, Japan) equipped with infrared differential interference contrast. Layer $2 / 3$ pyramidal cells were visually identified and patched using a whole-cell patch pipette (tip resistance, 3-5 M $\Omega$ ) filled with intracellular solution [containing (in $\mathrm{mM}$ ) 130 Cs-gluconate, $8 \mathrm{KCl}, 1$ EGTA, 10 HEPES, 4 ATP, and 5 QX-314 (lidocaine $N$-ethyl bromide), pH 7.4, 285-295 mOsm]. To isolate AMPA receptor-mediated miniature EPSCs (mEPSCs), $1 \mu \mathrm{M}$ tetrodotoxin (TTX), $20 \mu \mathrm{m}$ bicuculline, and $100 \mu \mathrm{M}$ D,L-APV were added to the ACSF $(2 \mathrm{ml} / \mathrm{min}$, $30 \pm 1^{\circ} \mathrm{C}$ ), which was continually bubbled with $95 \% \mathrm{O}_{2} / 5 \% \mathrm{CO}_{2}$. mEPSCs were recorded at a holding potential of $-80 \mathrm{mV}$ using an Axopatch-clamp amplifier (Molecular Devices, Union City, CA), digitized at $2 \mathrm{kHz}$ by a data acquisition board (National Instruments, Austin, TX), and acquired using the Igor Pro software (WaveMetrics, Lake Oswego, OR). Acquired mEPSCs were analyzed using the Mini Analysis program (Synaptosoft, Decatur, GA). The threshold for detecting mEPSCs was set at three times the root mean square (RMS) noise. There was no significant difference in RMS noise between the experimental groups (P13 NR, $1.8 \pm 0.09, n=10$; P13 DR, $2.0 \pm$ $0.07, n=10 ;$ t test,$p>0.1 ; \mathrm{P} 22 \mathrm{NR}, 1.8 \pm 0.1, n=9 ; \mathrm{P} 22 \mathrm{DR}, 1.7 \pm 0.07, n=$ $10 ; t$ test, $p>0.8 ; \mathrm{P} 23 \mathrm{NR}, 1.9 \pm 0.05, n=12 ; \mathrm{P} 23 \mathrm{DR}, 1.9 \pm 0.06, n=19 ; \mathrm{P} 24$ $\mathrm{D}+\mathrm{L}, 1.8 \pm 0.1, n=10$; ANOVA, $F_{(2,38)}=1.119, p>0.3$; P25 NR, $1.7 \pm$ $0.07, n=10$; P25 DR, $1.8 \pm 0.05, n=15 ; t$ test, $p>0.15$; P38 NR, $1.7 \pm 0.1$, $n=10$; P38 DR, $1.6 \pm 0.1, n=10$; P39 D $+\mathrm{L}, 1.8 \pm 0.1, n=10$; ANOVA, $F_{(2,27)}=0.684, p>0.5 ; \mathrm{P} 40 \mathrm{NR}, 1.9 \pm 0.1, n=11 ; \mathrm{P} 40 \mathrm{DR}, 1.8 \pm 0.7, n=$ $10 ; t$ test, $p>0.5 ; \mathrm{P} 97 \mathrm{NR}, 1.9 \pm 0.04, n=11 ; \mathrm{P} 97 \mathrm{DR}, 1.9 \pm 0.05, n=11 ; \mathrm{P} 98$ $\mathrm{D}+\mathrm{L}, 1.9 \pm 0.06, n=11$; ANOVA, $\left.F_{(2,30)}=0.546, p>0.6\right)$. A possibility of dendritic filtering was assessed by plotting mEPSC amplitude against mEPSC rise time. Cells showing a negative correlation between mEPSC amplitude and rise time (i.e., dendritic filtering present) were excluded from analysis, as well as mEPSCs with a $>3$ ms rise time (measured between 10 and $90 \%$ of amplitude). Average mEPSC amplitude and frequency were calculated and compared across different experimental groups using onefactor ANOVA or unpaired Student's $t$ test. Only the cells and recording conditions that met the following criteria were studied: $\mathrm{Vm} \leq-65 \mathrm{mV}$, input $R \geq 200 \mathrm{M} \Omega$, and series $R \leq 25 \mathrm{M} \Omega$. For older mice (P97), we only included cells that had a series $R \leq 20 \mathrm{M} \Omega$. Cells were discarded if input $R$ or series $R$ changed $>15 \%$. Junction potentials were typically $<5 \mathrm{mV}$ and were left uncompensated.

\section{Results}

Dark rearing for $2 \mathrm{~d}$ is necessary and sufficient to increase AMPA receptor-mediated $\mathrm{mEPSC}$ amplitude in layer 2/3 neurons

To compare homeostatic plasticity across ages, we first determined the minimal duration of visual deprivation that would $n=10 ; t$ test, $p>0.8$ ) (Fig. $1 a)$ or frequency (NR, $2.7 \pm 0.4 \mathrm{~Hz}$, $n=9 ; \mathrm{DR}, 2.5 \pm 0.2 \mathrm{~Hz}, n=10$; $t$ test, $p>0.7$ ) (Fig. $1 a$, top right) in layer $2 / 3$ visual cortical neurons. Consistent with previous results (Desai et al., 2002), 2 d of dark rearing significantly increased the mEPSC amplitude (P23, NR, $11.02 \pm 0.5 \mathrm{pA}, n=12$; DR, $13.4 \pm 0.5 \mathrm{pA}, n=19$; $t$ test, $p<0.004$ ) (Fig. $1 b$ ) without affecting mEPSC frequency (NR, $2.3 \pm 0.2 \mathrm{~Hz}, n=12$; DR, $2.5 \pm$ $0.3 \mathrm{~Hz}, n=19$; $t$ test, $p>0.6$ ) (Fig. $1 b$, top right) or kinetics (Table 1). These results suggest that dark rearing for at least $2 \mathrm{~d}$ is required to increase $\mathrm{mEPSC}$ amplitude. In addition, the increase in mEPSC amplitude without a change in frequency suggests that the locus of expression for homeostatic scaling is likely postsynaptic.

Next we examined whether $2 \mathrm{~d}$ of visual deprivation is sufficient to produce a maximal change in mEPSC amplitude. To do this, we increased the duration of dark rearing to $4 \mathrm{~d}$ (DR from $\mathrm{P} 21$ to $\mathrm{P} 25)$. As expected, this also significantly increased the mEPSC amplitude (NR, 9.8 $\pm 0.5 \mathrm{pA}, n=10$; DR, $14.1 \pm 0.9 \mathrm{pA}$, $n=15$; $t$ test, $p<0.0003$ ) (Fig. $1 c$ ) without changing mEPSC frequency $(\mathrm{NR}, 3.2 \pm 0.6 \mathrm{~Hz}, n=10$; DR, $2.7 \pm 0.4 \mathrm{~Hz}, n=15$; $t$ test, $p>0.5$ ) (Fig. $1 c$, top right). However, when we compared the average mEPSC amplitude after 2 and $4 \mathrm{~d}$ of dark rearing, there was no significant difference $(t$ test, $p>0.5)$. This implies that $2 \mathrm{~d}$ of dark rearing is sufficient to scale up neuronal responses maximally, and further deprivation of visual input does not lead to additional increases in synaptic strengths.

\section{Increase in AMPA receptor-mediated mEPSC amplitude by dark rearing is readily reversed by re-exposing the animals to light}

We have shown previously in juvenile rats that $2 \mathrm{~d}$ of re-exposure to light can reverse the increase in mEPSC amplitude caused by 1 week of dark rearing (Goel et al., 2006). Hence, we wanted to investigate whether reversible homeostatic synaptic changes can also be elicited in mice. To do this, mice were dark reared from P21 to P23 and then exposed to light for a day. Whole-cell recordings were then made from pyramidal cells in layer $2 / 3$ of visual cortex at P24. As shown in Figure 2, $1 \mathrm{~d}$ of re-exposure to light was able to reverse the increase in mEPSC amplitude by $2 \mathrm{~d}$ of dark rearing $(\mathrm{P} 23, \mathrm{NR}, 11.02 \pm 0.5 \mathrm{pA}, n=12 ; \mathrm{DR}, 13.4 \pm 0.5 \mathrm{pA}, n=$ 19; D $+\mathrm{L}, 9.2 \pm 0.5 \mathrm{pA}, n=10$; ANOVA, $F_{(2,38)}=15.757, p<$ 0.0001 ) (Fig. $2 a$ ) without alterations in mEPSC frequency (NR, 

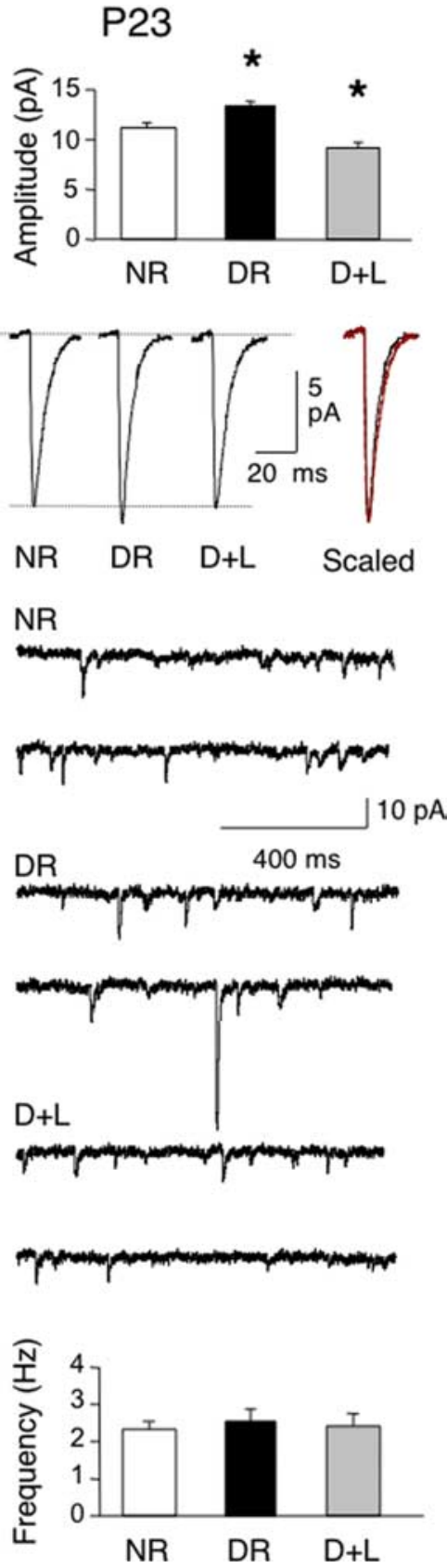

Figure 2. Reversible modification of AMPA receptor-mediated mEPSC amplitude in juvenile mice. Increase in $\mathrm{mEPSC}$ amplitude by $2 \mathrm{~d}$ of dark rearing was reversed by re-exposing the DR mice to light for $1 \mathrm{~d}(\mathrm{D}+\mathrm{L})$. Top, Comparison of average mEPSC amplitudes from NR, $2 \mathrm{~d} D \mathrm{DR}$, and $2 \mathrm{~d}$ DR followed by $1 \mathrm{~d}$ re-exposure to light $(\mathrm{D}+\mathrm{L})$. Middle, Average mEPSC traces from NR (left trace), DR (right trace), and D+L (right trace) mice. "Scaled" indicates the average mEPSC traces of NR (red solid line trace) and D $+\mathrm{L}$ (red dotted line trace) scaled and superimposed on the DR average trace (black trace). Note no difference in $m E P S C$ kinetics across the three groups. Below the average traces, representative traces of mEPSC recording obtained from layer $2 / 3$ pyramidal cells of normally reared P23 mice (top two traces), P21 mice dark reared for $2 \mathrm{~d}$ (middle two traces), and $2 \mathrm{~d}$ dark-reared P23 mice re-exposed to light for $1 \mathrm{~d}$ (bottom two traces) are shown. Bottom, No change in average mEPSC frequency across NR, DR, and D+L groups. * $p<0.0001$ with Fisher's PLSD post hoc test after one-way ANOVA.

$2.3 \pm 0.2 \mathrm{~Hz}, n=12 ; \mathrm{DR}, 2.5 \pm 0.3 \mathrm{~Hz}, n=19 ; \mathrm{D}+\mathrm{L}, 2.4 \pm 0.3$ $\mathrm{Hz}, n=10$; ANOVA, $F_{(2,38)}=0.134, p>0.6$ ) (Fig. $2 b$ ) or kinetics (Table 1). Collectively, our results show that manipulation of visual experience can reversibly affect homeostatic synaptic plasticity in juveniles.
Reversible homeostatic synaptic plasticity induced by visual experience persists in adults

Experience-dependent plasticity in the sensory cortex has been shown to operate within a distinct time window during development, known as the "critical period." Although, the tenet of "critical period plasticity" is rapidly being modified by the idea that synaptic reorganization does occur to some extent in the adult brain (Guire et al., 1999; Sawtell et al., 2003; Pham et al., 2004; He et al., 2006). A previous study on homeostatic synaptic scaling reported that visual deprivation-induced increase in $\mathrm{MEPSC}$ amplitude only occurred before P21 in layer 4 of the visual cortex, whereas layer $2 / 3 \mathrm{mEPSC}$ only scale up when visual deprivation started at P21 (Desai et al., 2002). This suggests that homeostatic synaptic scaling has distinct critical periods in different layers of the cortex. However, whether homeostatic synaptic plasticity in layer $2 / 3$ ends at a later developmental time point or persists throughout adulthood was not determined.

We first tested whether layer $2 / 3$ homeostatic synaptic plasticity has a defined critical period by studying the effects of dark rearing in P36 mice, which is just after the end of the critical period as defined by initial studies of ocular dominance plasticity $(\sim$ P32) (Gordon and Stryker, 1996). P36 mice were dark reared for a period of $2 \mathrm{~d}$ and then re-exposed to light for a day. Depriving vision for $2 \mathrm{~d}$ in P36 mice caused a significant increase in mEPSC amplitude, which rapidly reversed by $1 \mathrm{~d}$ of re-exposure to light (P38, NR, 9.6 $\pm 0.6 \mathrm{pA}, n=10 ; \mathrm{DR}, 14.5 \pm 1.1 \mathrm{pA}, n=10$; $\mathrm{D}+\mathrm{L}, 9.3 \pm 0.5 \mathrm{pA}, n=10 ;$ ANOVA, $\left.F_{(2,27)}=8.472, p<0.001\right)$ (Fig. $3 a$ ). There was no significant change in mEPSC frequency (P38, NR, $3.1 \pm 0.6 \mathrm{pA}, n=10$; DR, $3.6 \pm 0.6 \mathrm{pA}, n=10 ; \mathrm{D}+\mathrm{L}$, $2.8 \pm 0.6$ pA, $n=10$; ANOVA, $\left.F_{(2,27)}=0.501, p>0.6\right)$ (Fig. $3 b$ ) or mEPSC rise time (Table 1), but there was a significant change in the decay kinetics (Table 1).

Although an initial study of OD plasticity by brief MD reported that the critical period ends at $\sim$ P32 in mice (Gordon and Stryker, 1996), assessment of the effect of MD in rats using visually evoked potentials showed that OD plasticity extends to $\sim$ P50 (Guire et al., 1999). Moreover, previous reports showed that a slightly longer period of MD can produce significant OD shift in rats as old as P90 (Sawtell et al., 2003; Pham et al., 2004). Therefore, we decided to investigate homeostatic synaptic plasticity at a later age (P95). Similar to what we found in younger animals, dark rearing P95 mice for $2 \mathrm{~d}$ also caused a significant increase in mEPSC amplitude, which was reversed by re-exposure to light for $1 \mathrm{~d}(\mathrm{P} 97, \mathrm{NR}, 10.7 \pm 0.5 \mathrm{pA}, n=11 ; \mathrm{DR}, 13.1 \pm 0.8 \mathrm{pA}, n=11$; $\mathrm{D}+\mathrm{L}, 9.7 \pm 0.5 \mathrm{pA}, n=11 ;$ ANOVA, $\left.F_{(2,30)}=7.871, p<0.002\right)$ (Fig. $3 c$ ). This occurred without changes in mEPSC frequency (P97, NR, $2.5 \pm 0.4 \mathrm{pA}, n=11 ; \mathrm{DR}, 2.2 \pm 0.4 \mathrm{pA}, n=11 ; \mathrm{D}+\mathrm{L}$, $2.1 \pm 0.3 \mathrm{pA}, n=11$; ANOVA, $\left.F_{(2,30)}=0.36, p>0.7\right)($ Fig. $3 d)$ or rise time (Table 1 ), but there was a significant change in the decay kinetics (Table 1). These results demonstrate that layer $2 / 3$ retains the ability to undergo reversible homeostatic plasticity through adulthood.

\section{Loss of multiplicative synaptic scaling in adult mice}

Initial characterization of homeostatic synaptic scaling demonstrated that prolonged changes in neural activity result in a "multiplicative scaling” of synaptic weights (Turrigiano et al., 1998). Previous studies have reported that visual experience-driven homeostatic plasticity in juvenile rats also follows the rule of multiplicative scaling (Desai et al., 2002; Goel et al., 2006). However, there are also studies suggesting that homeostatic plasticity does not operate in a global multiplicative manner (Thiagarajan et al., 2005). Therefore, we wanted to examine whether the homeostatic 
synaptic plasticity we observe in mice occurs in a multiplicative manner across ages. To determine whether scaling up of synapses by visual deprivation occurs multiplicatively, we multiplied mEPSC amplitudes recorded from the normally reared group to match the average $\mathrm{mEPSC}$ amplitude of the DR group $\left(\mathrm{NR}_{\text {scaled }}\right)$, and compared them with mEPSC amplitudes measured from DR animals. Conversely, to test whether the decrease in synaptic weight by visual experience causes multiplicative scaling, we multiplied mEPSC amplitudes from the dark-reared group to match the average mEPSC amplitude of $\mathrm{D}+\mathrm{L}$ animals $\left(\mathrm{DR}_{\text {scaled }}\right)$, and compared them with the mEPSC amplitudes from the $\mathrm{D}+\mathrm{L}$ group.

We found that reversible changes in synaptic strength by visual experience in juvenile mice followed the rules of multiplicative scaling, but the changes in mEPSC amplitude in adults (especially in P97) did not occur in a global multiplicative manner. Comparison of the cumulative probability plots across different ages emphasizes the difference (Fig. 4). In P23 mice, the curve significantly shifts to the right with dark rearing (comparison of mEPSC amplitude between NR and DR, $p<0.0001$, Kolmogorov-Smirnov test) (Fig. 4a), and this shift is reversed with light exposure (comparison of mEPSC amplitude between DR and D+L, $p<$ 0.0001, Kolmogorov-Smirnov test) (Fig. $4 b)$. Superimposed on the graphs is a cumulative probability of mEPSC amplitudes from NR mice that are multiplied by a factor (1.2) to match the average mEPSC amplitude to that from DR mice $\left(\mathrm{NR}_{\text {scaled}}\right.$, red dotted line) (Fig. 4a). There was no statistically significant difference between the cumulative probability of DR and that of $\mathrm{NR}_{\text {scaled }}$ (Kolmogorov-Smirnov test, $p>0.5$ ) (Fig. $4 a$ ) or between $\mathrm{D}+\mathrm{L}$ and $\mathrm{DR}_{\text {scaled }}$ (Kolmogorov-Smirnov test, $p>$ 0.1 ) (Fig. 4b). This is consistent with a multiplicative scaling of synaptic strength as proposed by Turrigiano et al. (1998).

This multiplicative nature of synaptic strength modification is maintained in P38 mice for scaling up of synaptic strengths (Fig. 4c), but comparison of mEPSC amplitudes of $\mathrm{DR}_{\text {scaled }}$ and $\mathrm{D}+\mathrm{L}$ group was significantly different (Kolmogorov-Smirnov test, $p<0.01$ ) (Fig. $4 d$ ), implying that scaling down at this age does not occur in a global multiplicative manner. In P97 mice, both scaling up and scaling down of mEPSC amplitude did not follow a global multiplicative mechanism as exemplified by significant differences in mEPSC amplitude cumulative probability a
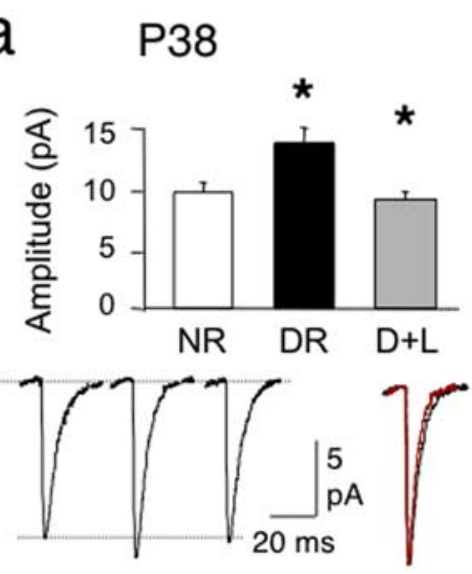

NR DR D+L Scaled

b

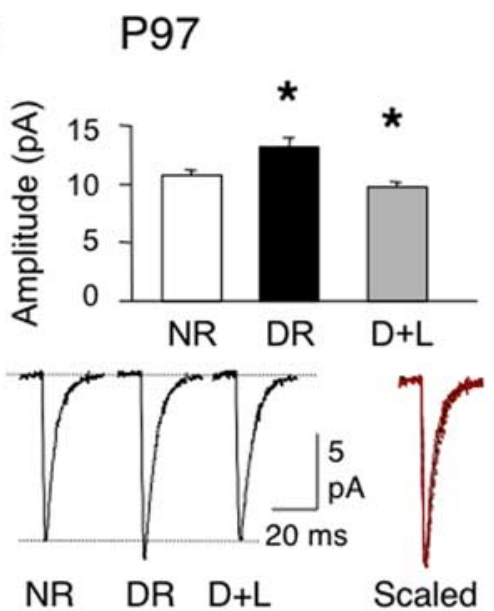

P38 NR
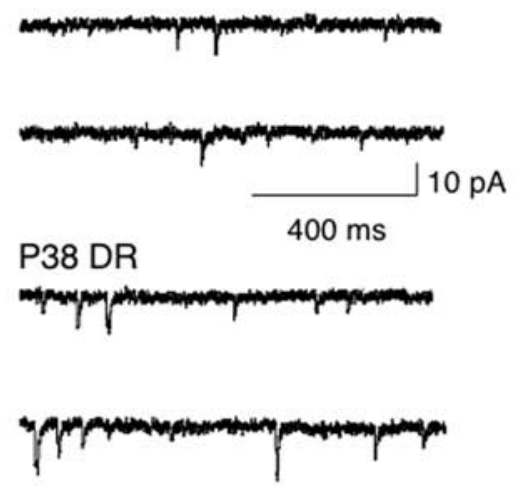

P38 D+L

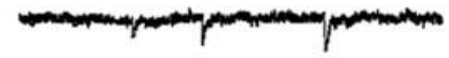

P97 D+L

P97 NR
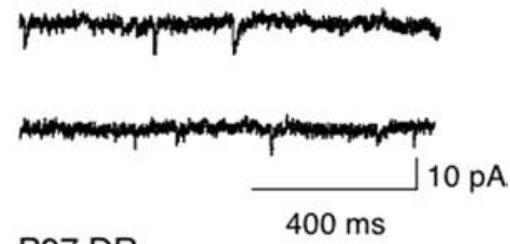

P97 DR
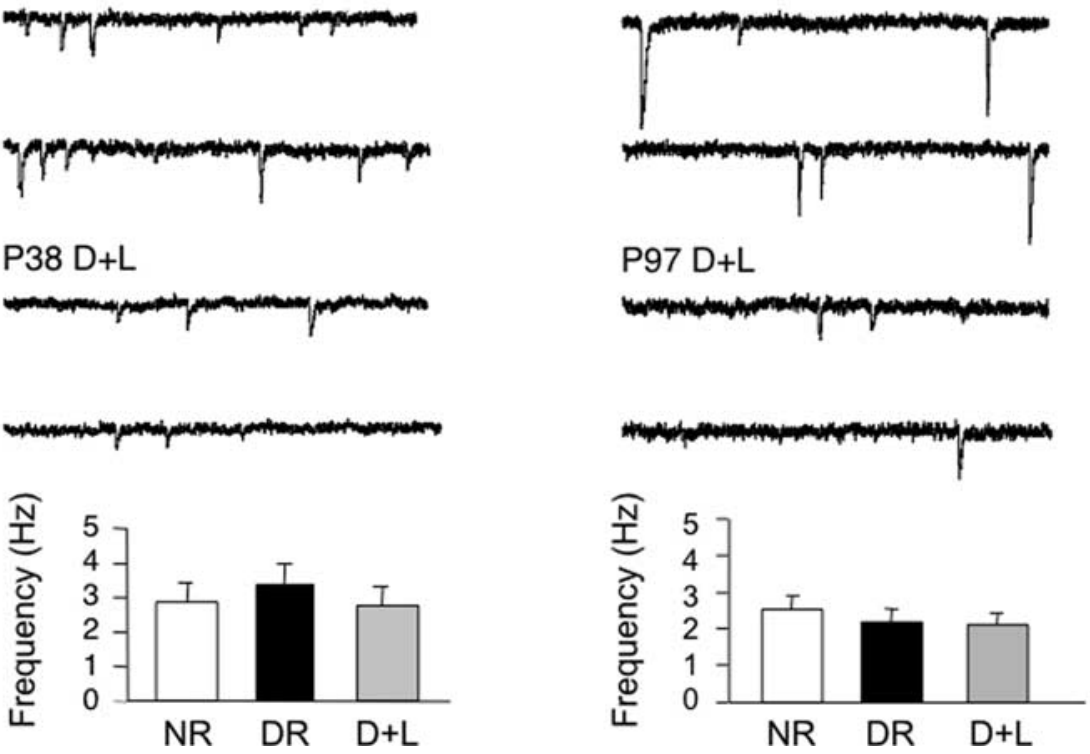

Figure 3. Reversible homeostatic synaptic modification in adult mice. $\boldsymbol{a}$, Dark rearing P36 mice for $2 \mathrm{~d}$ until P38 (DR) significantly increased mEPSC amplitude compared with NR, whereas $1 \mathrm{~d}$ of re-exposure to light $(D+L)$ reversed this increase. Top, Comparison of average mEPSC amplitude in NR, $2 \mathrm{~d}$ DR, and $2 \mathrm{~d}$ DR followed by $1 \mathrm{~d}$ re-exposure to $(\mathrm{D}+\mathrm{L})$ in P38 mice. Middle, Average mEPSC trace from NR (left trace), DR (middle trace), and D + L (right trace) groups. "Scaled" indicates that average mEPSC traces of NR (red solid trace) and D $+\mathrm{L}$ (red dotted trace) were scaled and superimposed on the average trace of DR (black trace). Below the average traces are the representative traces of $m E P S C$ recording obtained from layer $2 / 3$ pyramidal cell of normally reared P38 mice (top two traces), P36 mice dark reared for $2 \mathrm{~d}$ (middle two traces), and 2 d dark-reared P38 mice re-exposed to light for $1 \mathrm{~d}$ (bottom two traces). Bottom, No change in average mEPSC frequency across NR, DR, and D + L groups at P38. $\boldsymbol{b}$, Dark rearing for $2 \mathrm{~d}$ from P95 to P97 significantly increased mEPSC amplitude compared with NR, and this was reversed by $1 \mathrm{~d}$ of re-exposure to light $(D+L)$. Top, Comparison of average mEPSC amplitude between NR, $2 \mathrm{~d} D R$, and $2 \mathrm{~d}$ DR followed by $1 \mathrm{~d}$ of re-exposure to light $(D+L)$. Middle, Average mEPSC trace from NR (black trace), DR (black middle trace), and D+L (black right trace) mice. "Scaled" indicates the NR mEPSC average trace (red solid trace) and D+L mEPSC average trace (red dotted trace) scaled and superimposed on the DR average trace (black trace). Below the average mEPSC traces are representative traces of $\mathrm{mEPSC}$ recording obtained from layer 2/3 pyramidal cells of normally reared P97 mice (top two traces), P95 mice dark reared for $2 \mathrm{~d}$ (middle two traces), and 2 d dark-reared $P 97$ mice re-exposed to light for $1 \mathrm{~d}$ (bottom two traces). Bottom, No change in average mEPSC frequency across NR, DR, and D + L groups. ${ }^{*} p<0.003$ with Fisher's PLSD post hoc test after one-way ANOVA. 
a
P23 (NR, DR)

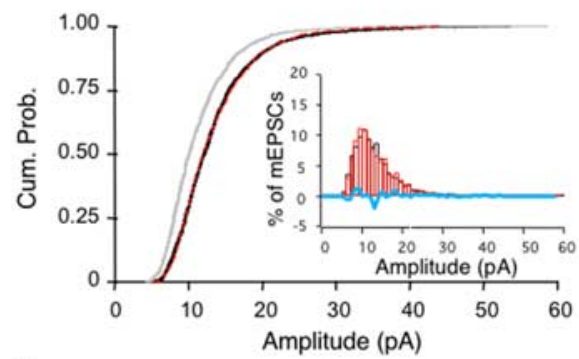

C

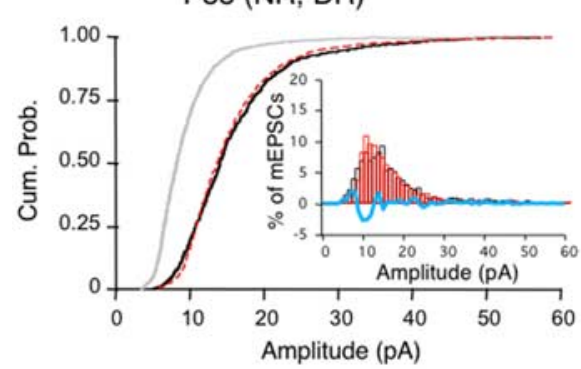

e

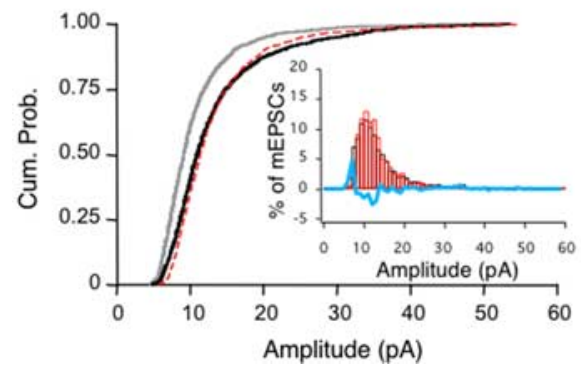

b

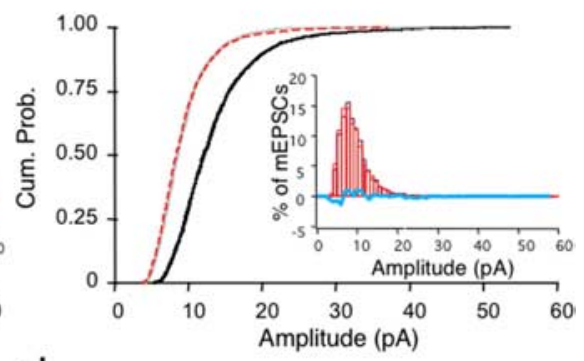

d

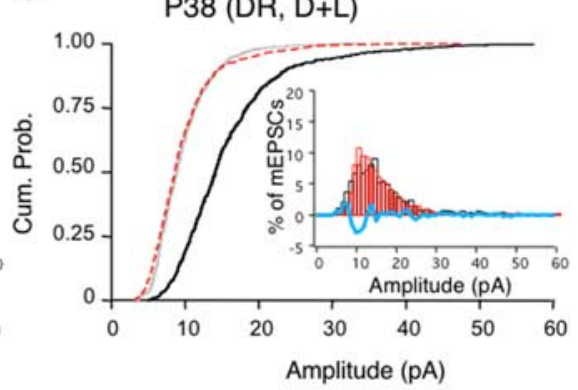

f

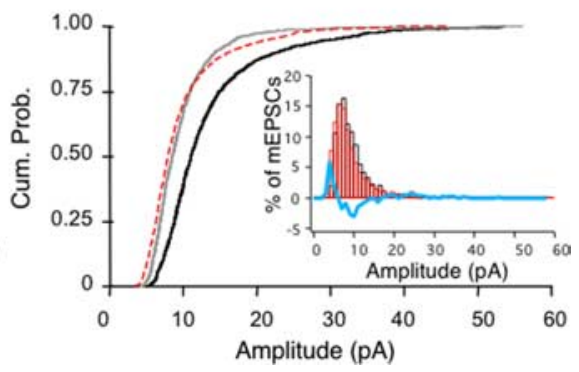

Figure 4. Loss of "multiplicative synaptic scaling" in adult mice. $\boldsymbol{a}$, Increase in mEPSC amplitude by $2 \mathrm{~d}$ of DR in P23 mice follows the rule of multiplicative scaling. Cumulative probability of mEPSC amplitudes (generated by compiling 100 consecutive mEPSCs from each neuron) in visual cortex neurons from P23 NR (gray solid line) and $2 \mathrm{~d}$ DR mice (black solid line). Superimposed on the graph is a cumulative probability of mEPSC amplitudes from NR that are multiplied by a factor (1.2) to match the average mEPSC amplitude of that from DR (NR scaled $_{\text {r }}$ red dotted line). There was no statistically significant difference between cumulative probability of DR and NR $\mathrm{N}_{\text {scaled }}$ (Kolmogorov-Smirnov test, $p>0.3$ ). Inset, Distribution histogram plotting the percentage of mEPSCs against $\mathrm{mEPSC}$ amplitude of $\mathrm{NR}_{\text {scaled }}$ (red bars) and DR (black bars). Superimposed on the graph is a subtraction of the two distributions (blue solid line). Note that there was no observable shift in distribution. $\boldsymbol{b}$, Decrease in mEPSC amplitude by reexposing $2 \mathrm{~d}$ DR mice to $1 \mathrm{~d}$ of light $(\mathrm{D}+\mathrm{L})$ in P23 mice also occurs in a multiplicative manner. Cumulative probability of mEPSC amplitudes from $2 \mathrm{~d}$ dark-reared P23 mice (DR, black solid line) and $2 \mathrm{~d}$ of DR followed by $1 \mathrm{~d}$ of light exposure ( $\mathrm{D}+\mathrm{L}$, gray solid line). Superimposed on the graph is a cumulative probability of mEPSC amplitudes from DR that are multiplied by a factor (0.7) to match the average $m E P S C$ amplitude of $D+L\left(D R_{\text {scaled, }}\right.$,ed dotted line). There was no statistically significant difference between the cumulative probability of $\mathrm{D}+\mathrm{L}$ and that of $D R_{\text {scaled }}$ (Kolmogorov-Smirnov test, $p>0.4$ ). Inset, Distribution histogram plotting the percentage of $m E P S C s$ against the $m E P S C$ amplitude of $D R_{\text {scaled }}$ (red bars) and $D+L$ (black bars). Superimposed on the graph is a subtraction of the two distributions (blue solid line). Note no noticeable shift in distribution. c, Multiplicative scaling of $\mathrm{mEPSC}$ amplitude by $2 \mathrm{~d}$ of DR is preserved in P38 mice. Cumulative probability of mEPSC amplitudes in visual cortex neurons from P38 NR (gray solid line) and $2 \mathrm{~d}$ DR (black solid line) is shown. Superimposed on the graph is a cumulative probability of mEPSC amplitudes from NR that are multiplied by a factor (1.6) to match the average $\mathrm{mEPSC}$ amplitude of DR (NR scaled $_{\text {r }}$ red dotted line).

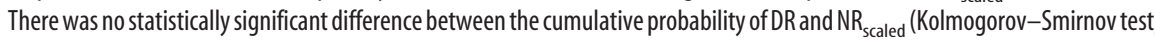
$p>0.1$ ). Inset, Distribution histogram plotting the percentage of mEPSCs against $m E P S C$ amplitude of $N_{\text {scaled }}$ (red bars) and DR (black bars). Superimposed on the graph is a subtraction of the two distributions (blue solid line). Note that there were a bit more fluctuations in the subtraction graph when compared with that seen at P23 (inset in $\boldsymbol{a}$ ). $\boldsymbol{d}$, Reversal of DR-induced increase in mEPSC amplitude by re-exposure to light $(\mathrm{D}+\mathrm{L})$ does not conform to the multiplicative scaling mechanism. Cumulative probability of mEPSC amplitudes in visual cortex neurons from P38 DR (black solid line) and dark-reared followed by $1 \mathrm{~d}$ of light re-exposure ( $D+L$, gray solid line) is shown. Superimposed is a cumulative probability of mEPSC amplitudes from DR that are multiplied by a factor (0.6) to match the average mEPSC amplitude of $D+L\left(D R_{\text {scaled }}\right.$, red dotted line). There was a statistically significant difference between the cumulative probability of $D+L_{\text {and }} \mathrm{RR}_{\text {scaled }}$ (Kolmogorov-Smirnov test, $p<0.01$ ), suggesting that the reduction in mEPSC amplitude by re-exposure to light does not follow the rules of multiplicative synaptic scaling. Inset, Distribution histogram plotting the percentage of mEPSCs against $m E P S C$ amplitude of $D R_{\text {scaled }}$ (red bars) and $D+L$ (black bars). Superimposed on the graph is a subtraction of the two distributions (blue solid line). Note that there was a more noticeable difference in distribution as seen in the subtraction graph than in $\mathrm{P} 38 \mathrm{NR}_{\text {scaled }}$ to DR comparison (inset in c). $\boldsymbol{e}$, Increase in $\mathrm{mEPSC}$ of DR and $\mathrm{NR}_{\text {scaled }}$ (Kolmogorov-Smirnov test, $p<0.0001$ ) (Fig. 4e) and between $\mathrm{NR}$ and $\mathrm{D}+\mathrm{L}_{\text {scaled }}$ (Kolmogorov-Smirnov test, $p<0.0001$ ) (Fig. $4 f$ ). To further ensure that the nonmultiplicative nature of synaptic scaling in $\mathrm{P} 97$ group was not attributable to an artifact of amplitude detection cutoff, we reanalyzed our data following the technique described by Turrigiano et al. (1998). This also confirmed a significant difference in mEPSC amplitude between DR and $\mathrm{NR}_{\text {scaled }}$ (Kolmogorov-Smirnov test, $p<0.002$ ) (supplemental Fig. $2 a$, available at www.j neurosci.org as supplemental material) and between $\mathrm{DR}_{\text {scaled }}$ and $\mathrm{D}+\mathrm{L}$ animals (Kolmogorov-Smirnov test, $p<0.001$ ) (supplemental Fig. 2b, available at www.jneurosci.org as supplemental material). Collectively, our data suggest that although visual experience in juvenile mice globally changes synaptic weights in a multiplicative manner, not all synapses in adults are being modified this way.

\section{$\leftarrow$}

amplitude by $2 \mathrm{~d}$ of DR in P97 mice does not occur in a multiplicative manner. Cumulative probability of mEPSC amplitudes in visual cortex neurons from P97 NR (gray solid line) and $2 \mathrm{~d}$ DR mice (black solid line) are plotted. Superimposed on the graph is a cumulative probability of mEPSC amplitudes from NR mice that are multiplied by a factor (1.2) to match the average $m E P S C$ amplitude of DR mice $\left(\mathrm{NR}_{\text {scaled, }}\right.$, red dotted line). There was a statistically significant difference between the cumulative probability of DR and $\mathrm{NR}_{\text {scaled }}$ (KolmogorovSmirnov test, $p<0.001)$. This suggests that global multiplicative scaling mechanism does not operate at this age. Inset, Distribution histogram plotting the percentage of mEPSCs against $m$ EPSC amplitude of $\mathrm{NR}_{\text {scaled }}$ (red bars) and DR (black bars). Note that there was an observable shift in distribution between $\mathrm{NR}_{\text {scaled }}$ and $\mathrm{DR}$, which is shown as a large positive peak followed by a depression in the superimposed subtraction graph (blue solid line). $f$, Decrease in mEPSC amplitude by re-exposing DR mice to $1 \mathrm{~d}$ of light $(\mathrm{D}+\mathrm{L})$ at $\mathrm{P9} 7$ also does not occur via a global multiplicative scaling mechanism. Cumulative probability of $m E P S C$ amplitudes in visual cortex neurons from P97 DR mice (black solid line) and DR mice followed by $1 \mathrm{~d}$ of light exposure $(D+L$, gray solid line) are shown. Superimposed on the graph is a cumulative probability of mEPSC amplitudes from DR mice that are multiplied by a factor (0.7) to match the average mEPSC amplitude of D+L mice (DRscaled , red dotted line). There was a statistically significant difference between the cumulative probability of DR and $D+L_{\text {scaled }}$ (Kolmogorov-Smirnov test, $p<0.001$ ). This suggests that a global multiplicative scaling down does not occur at this age. Inset, Distribution histogram plotting the percentage of mEPSCs against the mEPSC amplitude of DR scaled $_{\text {(red }}$ bars) and $\mathrm{D}+\mathrm{L}$ (black bars). Note that there was an observable shift in the distribution between $N R_{\text {scaled }}$ and DR, which is shown as a large positive peak followed by a depression in the superimposed subtraction graph (blue solid line). 

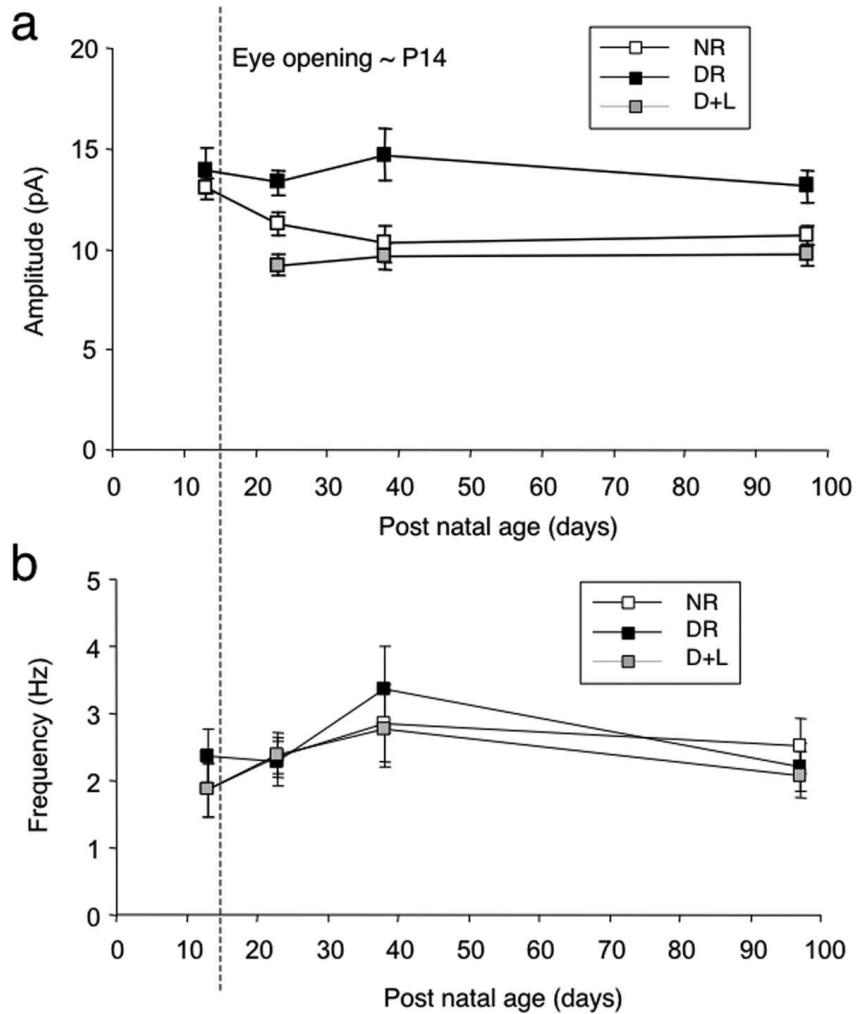

Figure 5. Persistence of experience-induced reversible changes in $\mathrm{mEPSC}$ amplitude in the superficial layers of visual cortex. $\boldsymbol{a}$, Comparison of average mEPSC amplitudes during development in NR (open squares), $2 \mathrm{~d}$ DR (black squares), and $2 \mathrm{~d} D$ R re-exposed to $1 \mathrm{~d}$ light ( $\mathrm{D}+\mathrm{L}$ : gray squares) mice. Black dashed line indicates eye opening, which occurs around P14 in mice. There was a developmental decrease in average mEPSC amplitude that occurred after eye opening (after P13), which plateaus around P21 (one-way ANOVA, $F_{(3,39)}=3.249, p<0.04$ ). There was no change in $\mathrm{mEPSC}$ amplitude with $2 \mathrm{~d}$ of DR before eye opening, whereas in all other ages recorded, we saw significant increases in $\mathrm{mEPSC}$ amplitude. This increase in amplitude was reversed by $1 \mathrm{~d}$ of light exposure. $\boldsymbol{b}$, Comparison of average mEPSC frequency across age in NR (open squares), $2 \mathrm{~d}$ DR (black squares), and DR mice re-exposed to $1 \mathrm{~d}$ light ( $\mathrm{D}+\mathrm{L}$; gray squares). There was no significant difference in mEPSC frequency across normal development or between $N R$, $D R$, and $D+L$ mice regardless of age.

\section{Dark rearing does not produce homeostatic synaptic scaling before eye opening}

Many aspects of visual cortex development are induced by experience and, hence, occur after eye opening (Blue and Parnavelas, 1983; Cancedda et al., 2003; Yoshii et al., 2003). However, some aspects of visual system organization occur before eye opening (Katz and Shatz, 1996; Penn et al., 1998; Crowley and Katz, 2000). Therefore, to examine whether visual cortical neurons in very young animals undergo experience-dependent synaptic scaling, we measured mEPSCs from mice before eye opening. Eye opening in mice occurs around P14; hence, we looked at P13 animals. Average mEPSC amplitudes from layer $2 / 3$ cells of $\mathrm{P} 13$ mice were larger than those recorded from P23 animals (P13, NR, $13.1 \pm 0.5$ $\mathrm{pA}, n=10$; P23, NR, $11.02 \pm 0.5 \mathrm{pA}, n=12$; $t$ test, $p<0.02$ ). Furthermore, dark rearing mice from P11 until P13 (2 d DR) did not alter mEPSC amplitude (P13, NR, $13.1 \pm 0.5 \mathrm{pA}, n=10$; DR, $13.9 \pm 1.1 \mathrm{pA}, n=12$; $t$ test, $p>0.5$ ) (Fig. $5 a$ ) or frequency (P13, $\mathrm{NR}, 1.9 \pm 0.4 \mathrm{pA}, n=10 ; \mathrm{DR}, 2.4 \pm 0.4 \mathrm{pA}, n=12 ; t$ test, $p>0.4)$ (Fig. $5 b$ ) in layer $2 / 3$ neurons. These results suggest that synaptic strength before eye opening may be scaled to the maximum, and dark rearing does not cause any additional increase.

\section{Discussion}

We found that experience-induced reversible homeostatic synaptic plasticity persists through adulthood in the superficial layers of mouse visual cortex. The minimum duration of binocular visual deprivation necessary and sufficient to induce a maximal homeostatic modification was $2 \mathrm{~d}$. Visual deprivation-induced increase in AMPA receptor function was rapidly reversed when vision was restored by re-exposing animals to $1 \mathrm{~d}$ of light. Our summary data show that average mEPSC amplitude was larger in young animals before eye opening, which then decreases to plateau around the third postnatal week (Fig. 5a). However, mEPSC frequency remained essentially the same across ages with only a trend toward an increase (Fig. 5b), suggesting postsynaptic loci for change. Dark rearing-induced homeostatic mechanisms were not operative before eye opening and, in essence, visual deprivation at later ages seems to return mEPSC amplitude to that seen before eye opening (Fig. 5a). Although reversible homeostatic synaptic changes are observed in adults, we find evidence that the mechanism of homeostatic plasticity differs from juvenile mice in that it no longer occurs globally by a multiplicative scaling mechanism.

Our results show that in young mice (at P21), $2 \mathrm{~d}$ of dark rearing is necessary and sufficient for inducing homeostatic synaptic plasticity. This result is consistent with previous in vitro findings where $2 \mathrm{~d}$ of TTX application to cortical cultures maximally scales up AMPA receptor-mediated mEPSCs (Turrigiano et al., 1998). Our observation is not likely complicated by developmental issues, because $2 \mathrm{~d}$ of dark rearing also maximally increased mEPSC amplitude in more mature animals (dark rearing initiated at P36) (supplemental Fig. 1, available at www. jneurosci.org as supplemental material), where there is little developmental change in average mEPSC amplitude (Fig. 5a).

In vitro studies showed that homeostatic plasticity driven by pharmacological manipulation of neural activity is bidirectional (Lissin et al., 1998; O’Brien et al., 1998; Turrigiano et al., 1998; Thiagarajan et al., 2002). Previously, we reported that manipulation of visual experience can also reversibly regulate synaptic scaling in juvenile rat visual cortical slices (Goel et al., 2006). The present study extends these findings to show that the reversible nature of experience-induced homeostatic regulation is operative in mice, and also elucidated the minimum duration required for producing homeostatic synaptic scaling by experience. Interestingly, whereas $2 \mathrm{~d}$ of visual deprivation was required to scale up synaptic strengths, only $1 \mathrm{~d}$ of visual experience was sufficient to reverse this change. This may illustrate differences in the mechanisms of synaptic scaling up versus down. Although there are data supporting reversible changes in AMPA receptor subunit composition (Thiagarajan et al., 2005; Goel et al., 2006), and the calcium/calmodulin-dependent protein kinase II $\alpha(\mathrm{CaMKII} \alpha) /$ CaMKII $\beta$ ratio (Thiagarajan et al., 2002) during bidirectional homeostatic plasticity, previous evidence supports the notion of asymmetry in molecular mechanisms. For instance, a previous study demonstrated that tumor-necrosis factor- $\alpha$ is only involved in synaptic scaling up of excitatory synaptic transmission by inactivity, and not for scaling down synapses by enhanced activity in hippocampal cultures (Stellwagen and Malenka, 2006). In contrast, Arc/Arg 3.1 (activity-regulated cytoskeletal protein/activity-regulated gene 3.1), which is an immediate early gene rapidly upregulated by neural activity (Lyford et al., 1995), has been shown to be involved in scaling down synapses (Shepherd et al., 2006). Asymmetry in homeostatic plasticity mechanisms also seems to occur in vivo, because we reported that in- 
crease in phosphorylation of AMPA receptor subunit GluR1 (glutamate receptor 1 ) at serine 845 by dark rearing does not reverse with re-exposure to light (Goel et al., 2006).

One of our major findings is that reversible homeostatic plasticity induced by visual experience in the superficial layers of the visual cortex can occur through adulthood, well beyond the "classical" critical period. Initial studies of cortical plasticity emphasized the sharp loss of plasticity around puberty, as defined as the critical period (for review, see Berardi et al., 2000). However, previous studies demonstrate that a substantial level of visual cortex plasticity remains in adulthood (Guire et al., 1999; Sawtell et al., 2003; Pham et al., 2004), especially in the superficial layers of the cortex (Guire et al., 1999; Pham et al., 2004). Moreover, certain manipulations, such as visual deprivation (He et al., 2006) or degradation of the extracellular matrix (Pizzorusso et al., 2002; Berardi et al., 2004) or knock-out of Nogo signaling (McGee et al., 2005), enhance OD plasticity in adults. Adult plasticity is not restricted to the visual cortex. Although initial studies on plasticity in the barrel cortex showed that there is a critical period for experience-dependent plasticity (Fox, 1992), further investigations showed that barrel cortex receptive fields can be altered by experience in adult rats (Diamond et al., 1993; Glazewski et al., 1996; Wallace et al., 2001; Fox, 2002; Polley et al., 2004). Furthermore, a previous finding showed that a brief exposure to an enriched environment can accelerate barrel cortex receptive field plasticity in adult rats (Rema et al., 2006). Interestingly, dendritic spines, which are considered to be the morphological correlates of experience-dependent synaptic plasticity, continue to turnover in both visual and somatosensory cortices even in adults (Grutzendler et al., 2002; Trachtenberg et al., 2002; Holtmaat et al., 2005, 2006; Zuo et al., 2005), albeit to a lesser extend than in young animals (Grutzendler et al., 2002; Holtmaat et al., 2005; Zuo et al., 2005).

Although adult plasticity is observed in different sensory cortices, the majority of studies indicate that different cortical layers have varying capacities to undergo plasticity. Specifically, layer 4 is known to mature earlier than extragranular layers and, hence, display a short and well defined critical period for sensory plasticity. In cats, the critical period for layer 4 in the visual cortex ends at $\sim 8$ months of age (Daw et al., 1992) whereas in the mouse barrel cortex layer 4 matures by P12 (Stern et al., 2001). In contrast, superficial layers seem to have an extended critical period for OD plasticity that lasts longer than in layer 4 . In cat visual cortex, extragranular layers remain plastic up to 1 year (Daw et al., 1992), and in the barrel cortex the critical period for layer $2 / 3$ spans between P12 and P14 (Stern et al., 2001). Similarly, homeostatic synaptic scaling also exhibits layer-specific critical periods. Monocular deprivation by TTX injections between P14 and P16 produced synaptic scaling in layer 4 , but not in layers $2 / 3$ of the visual cortex (Desai et al., 2002). In contrast, the same monocular deprivation paradigm performed between the ages P21 and P23 failed to produce synaptic scaling in layer 4 , but caused homeostatic scaling in layer 2/3 (Desai et al., 2002). Collectively, these results suggest that layer 4 plasticity (whether it be OD plasticity or homeostatic synaptic scaling) is more limited to early development, whereas layer $2 / 3$ plasticity seems to last longer. Our data extends these studies to demonstrate that experienceinduced homeostatic plasticity in layer $2 / 3$ persists through adulthood.

Although reversible homeostatic plasticity persists in layers $2 / 3$ of visual cortex in adults, the mechanism seems to differ from that in young animals. Initial descriptions of homeostatic synaptic scaling in cortical cultures by Turrigiano et al. (1998) demon- strated that scaling occurs via a multiplicative mechanism. Therefore, all synapses on a cell globally scale up or down with the same multiplicative factor. We reported previously that this is also the case for visual experience-induced homeostatic plasticity in the juvenile rat visual cortex (Goel et al., 2006). In contrast, work using hippocampal cultures showed that homeostatic changes differentially modify subsets of synapses, which implies that they do not follow a strict global multiplicative mechanism (Thiagarajan et al., 2005). We found that experience-induced reversible homeostatic plasticity in visual cortex occurs via a global multiplicative mechanism in young animals (P23), but not in adults (especially at P97), suggesting that age may be a determining factor. Incidentally, there were statistically significant changes in mEPSC decay kinetics with visual manipulations only in adults (Table 1), which further implies a potential difference with age. Similarly, a previous study demonstrated that an increase in the in vitro age of neuronal cultures causes the expression locus of homeostatic plasticity to shift from predominantly postsynaptic to having both presynaptic and postsynaptic components (Wierenga et al., 2006). Interestingly, spines turnover more slowly in the visual cortex of adult mice (Grutzendler et al., 2002; Holtmaat et al., 2005), implying that there may be a smaller proportion of dynamic synapses that undergo activity-dependent modifications. Therefore, we surmise that visual experience may preferentially affect this dynamic population of synapses in the adult cortex. Previous studies highlighted that synapses on neocortical neurons may use different rules for inducing synaptic plasticity, depending on their dendritic location (Froemke et al., 2005; Gordon et al., 2006; Letzkus et al., 2006; Sjostrom and Hausser, 2006). Therefore, it is also plausible that there may be select dendritic compartments that undergo homeostatic plasticity in adults. In any case, the nonmultiplicative scaling in adults occurred without alterations in mEPSC frequency, suggesting that a subset of pre-existing synapses likely undergo homeostatic changes. Collectively, our results suggest that there is persistent homeostatic regulation of synapses through adulthood in the superficial layers of the visual cortex, but that the mechanisms change, perhaps because of the different computational requirements that neural networks need to fulfill as the animals mature.

\section{References}

Abbott LF, Nelson SB (2000) Synaptic plasticity: taming the beast. Nat Neurosci [Suppl 3]:1178-1183.

Bear MF, Cooper LN, Ebner FF (1987) A physiological basis for a theory of synapse modification. Science 237:42-48.

Berardi N, Pizzorusso T, Maffei L (2000) Critical periods during sensory development. Curr Opin Neurobiol 10:138-145.

Berardi N, Pizzorusso T, Maffei L (2004) Extracellular matrix and visual cortical plasticity: freeing the synapse. Neuron 44:905-908.

Bienenstock EL, Cooper LN, Munro PW (1982) Theory for the development of neuron selectivity: orientation specificity and binocular interaction in visual cortex. J Neurosci 2:32-48.

Bliss TV, Collingridge GL (1993) A synaptic model of memory: long-term potentiation in the hippocampus. Nature 361:31-39.

Blue ME, Parnavelas JG (1983) The formation and maturation of synapses in the visual cortex of the rat. I. Qualitative analysis. J Neurocytol 12:599-616.

Cancedda L, Putignano E, Impey S, Maffei L, Ratto GM, Pizzorusso T (2003) Patterned vision causes CRE-mediated gene expression in the visual cortex through PKA and ERK. J Neurosci 23:7012-7020.

Crowley JC, Katz LC (2000) Early development of ocular dominance columns. Science 290:1321-1324.

Daw NW, Fox K, Sato H, Czepita D (1992) Critical period for monocular deprivation in the cat visual cortex. J Neurophysiol 67:197-202.

Desai NS, Cudmore RH, Nelson SB, Turrigiano GG (2002) Critical periods for experience-dependent synaptic scaling in visual cortex. Nat Neurosci 5:783-789. 
Diamond ME, Armstrong-James M, Ebner FF (1993) Experiencedependent plasticity in adult rat barrel cortex. Proc Natl Acad Sci USA 90:2082-2086.

Fox K (1992) A critical period for experience-dependent synaptic plasticity in rat barrel cortex. J Neurosci 12:1826-1838.

Fox K (2002) Anatomical pathways and molecular mechanisms for plasticity in the barrel cortex. Neuroscience 111:799-814.

Froemke RC, Poo MM, Dan Y (2005) Spike-timing-dependent synaptic plasticity depends on dendritic location. Nature 434:221-225.

Glazewski S, Chen CM, Silva A, Fox K (1996) Requirement for alphaCaMKII in experience-dependent plasticity of the barrel cortex. Science 272:421-423.

Goel A, Jiang B, Xu LW, Song L, Kirkwood A, Lee HK (2006) Cross-modal regulation of synaptic AMPA receptors in primary sensory cortices by visual experience. Nat Neurosci 9:1001-1003.

Gordon JA, Stryker MP (1996) Experience-dependent plasticity of binocular responses in the primary visual cortex of the mouse. J Neurosci 16:3274-3286.

Gordon U, Polsky A, Schiller J (2006) Plasticity compartments in basal dendrites of neocortical pyramidal neurons. J Neurosci 26:12717-12726.

Grutzendler J, Kasthuri N, Gan WB (2002) Long-term dendritic spine stability in the adult cortex. Nature 420:812-816.

Guire ES, Lickey ME, Gordon B (1999) Critical period for the monocular deprivation effect in rats: assessment with sweep visually evoked potentials. J Neurophysiol 81:121-128.

He HY, Hodos W, Quinlan EM (2006) Visual deprivation reactivates rapid ocular dominance plasticity in adult visual cortex. J Neurosci 26:2951-2955.

Holtmaat A, Wilbrecht L, Knott GW, Welker E, Svoboda K (2006) Experience-dependent and cell-type-specific spine growth in the neocortex. Nature 441:979-983.

Holtmaat AJ, Trachtenberg JT, Wilbrecht L, Shepherd GM, Zhang X, Knott GW, Svoboda K (2005) Transient and persistent dendritic spines in the neocortex in vivo. Neuron 45:279-291.

Hubel DH (1982) Exploration of the primary visual cortex, 1955-78. Nature 299:515-524.

Ju W, Morishita W, Tsui J, Gaietta G, Deerinck TJ, Adams SR, Garner CC, Tsien RY, Ellisman MH, Malenka RC (2004) Activity-dependent regulation of dendritic synthesis and trafficking of AMPA receptors. Nat Neurosci 7:244-253.

Katz LC, Shatz CJ (1996) Synaptic activity and the construction of cortical circuits. Science 274:1133-1138.

Letzkus P, Ribi WA, Wood JT, Zhu H, Zhang SW, Srinivasan MV (2006) Lateralization of olfaction in the honeybee Apis mellifera. Curr Biol 16:1471-1476.

LeVay S, Wiesel TN, Hubel DH (1980) The development of ocular dominance columns in normal and visually deprived monkeys. J Comp Neurol 191:1-51.

Lissin DV, Gomperts SN, Carroll RC, Christine CW, Kalman D, Kitamura M, Hardy S, Nicoll RA, Malenka RC, von Zastrow M (1998) Activity differentially regulates the surface expression of synaptic AMPA and NMDA glutamate receptors. Proc Natl Acad Sci USA 95:7097-7102.

Lyford GL, Yamagata K, Kaufmann WE, Barnes CA, Sanders LK, Copeland NG, Gilbert DJ, Jenkins NA, Lanahan AA, Worley PF (1995) Arc, a growth factor and activity-regulated gene, encodes a novel cytoskeletonassociated protein that is enriched in neuronal dendrites. Neuron 14:433-445.

Malenka RC, Bear MF (2004) LTP and LTD: an embarrassment of riches. Neuron 44:5-21.

McGee AW, Yang Y, Fischer QS, Daw NW, Strittmatter SM (2005)
Experience-driven plasticity of visual cortex limited by myelin and Nogo receptor. Science 309:2222-2226.

O’Brien RJ, Kamboj S, Ehlers MD, Rosen KR, Fischbach GD, Huganir RL (1998) Activity-dependent modulation of synaptic AMPA receptor accumulation. Neuron 21:1067-1078.

Penn AA, Riquelme PA, Feller MB, Shatz CJ (1998) Competition in retinogeniculate patterning driven by spontaneous activity. Science 279:2108-2112.

Pham TA, Graham SJ, Suzuki S, Barco A, Kandel ER, Gordon B, Lickey ME (2004) A semi-persistent adult ocular dominance plasticity in visual cortex is stabilized by activated CREB. Learn Mem 11:738-747.

Pizzorusso T, Medini P, Berardi N, Chierzi S, Fawcett JW, Maffei L (2002) Reactivation of ocular dominance plasticity in the adult visual cortex. Science 298:1248-1251.

Polley DB, Kvasnak E, Frostig RD (2004) Naturalistic experience transforms sensory maps in the adult cortex of caged animals. Nature 429:67-71.

Rema V, Armstrong-James M, Jenkinson N, Ebner FF (2006) Short exposure to an enriched environment accelerates plasticity in the barrel cortex of adult rats. Neuroscience 140:659-672.

Sawtell NB, Frenkel MY, Philpot BD, Nakazawa K, Tonegawa S, Bear MF (2003) NMDA receptor-dependent ocular dominance plasticity in adult visual cortex. Neuron 38:977-985.

Shepherd JD, Rumbaugh G, Wu J, Chowdhury S, Plath N, Kuhl D, Huganir RL, Worley PF (2006) Arc/Arg3.1 mediates homeostatic synaptic scaling of AMPA receptors. Neuron 52:475-484.

Sjostrom PJ, Hausser M (2006) A cooperative switch determines the sign of synaptic plasticity in distal dendrites of neocortical pyramidal neurons. Neuron 51:227-238.

Stellwagen D, Malenka RC (2006) Synaptic scaling mediated by glial TNFalpha. Nature 440:1054-1059.

Stern EA, Maravall M, Svoboda K (2001) Rapid development and plasticity of layer 2/3 maps in rat barrel cortex in vivo. Neuron 31:305-315.

Thiagarajan TC, Piedras-Renteria ES, Tsien RW (2002) alpha- and betaCaMKII. Inverse regulation by neuronal activity and opposing effects on synaptic strength. Neuron 36:1103-1114.

Thiagarajan TC, Lindskog M, Tsien RW (2005) Adaptation to synaptic inactivity in hippocampal neurons. Neuron 47:725-737.

Trachtenberg JT, Chen BE, Knott GW, Feng G, Sanes JR, Welker E, Svoboda $\mathrm{K}$ (2002) Long-term in vivo imaging of experience-dependent synaptic plasticity in adult cortex. Nature 420:788-794.

Turrigiano GG, Nelson SB (2004) Homeostatic plasticity in the developing nervous system. Nat Rev Neurosci 5:97-107.

Turrigiano GG, Leslie KR, Desai NS, Rutherford LC, Nelson SB (1998) Activity-dependent scaling of quantal amplitude in neocortical neurons. Nature 391:892-896.

Wallace H, Glazewski S, Liming K, Fox K (2001) The role of cortical activity in experience-dependent potentiation and depression of sensory responses in rat barrel cortex. J Neurosci 21:3881-3894.

Wierenga CJ, Walsh MF, Turrigiano GG (2006) Temporal regulation of the expression locus of homeostatic plasticity. J Neurophysiol 96:2127-2133.

Wiesel TN, Hubel DH (1963) Effects of visual deprivation on morphology and physiology of cells in the cats lateral geniculate body. J Neurophysiol 26:978-993.

Yoshii A, Sheng MH, Constantine-Paton M (2003) Eye opening induces a rapid dendritic localization of PSD-95 in central visual neurons. Proc Natl Acad Sci USA 100:1334-1339.

Zuo Y, Yang G, Kwon E, Gan WB (2005) Long-term sensory deprivation prevents dendritic spine loss in primary somatosensory cortex. Nature 436:261-265. 